\title{
Differences In Learning Preferences Among Medical, Dental And DPT Students
}

Amtul Anum, Tabassum Ahsan Qadeer

ABSTRACT:

Objective: To analyze the learning styles of undergraduate medical, dental and DPT (Department of physical therapy) students using the VARK questionnaire.

Study Design and Setting: This cross sectional questionnaire based clinical study was conducted on 278 undergraduate students at Bahria University of Medical and Dental College in Karachi.

Methodology: 150 medical, 100 dental and 28 DPT students were asked to complete VARK (Visual, Auditory, Read-write and Kinesthetic) questionnaire and their learning preferences were studied. Percentages were formulated and outcomes of each group were paralleled to conclude the result. The data was assessed using SPSS software, version 23. Statistical associations among MBBS, BDS and DPT students and gender preferences were made using chi square analysis and comparison between academic years was made with Fisher's exact test. $\mathrm{P}<0.05$ was considered significant.

Results: Our result showed that $76.3 \%$ preferred unimodal style followed by bimodal (18.3\%) and trimodal (5.4\%). Kinesthetic (40\%) was the most preferred method followed by aural $(36 \%)$. There was no preferential shift with gender or academic year variation.

Conclusion: According to our study, most of the undergraduate medical, dental and DPT students prefer unimodal method of learning despite of educational, gender and academic variation in the sample. None of the students preferred the quadmodal learning style. Kinesthetic was the most preferred unimodal preference.

Keywords: Vark, Learning Preferences, Teaching Strategy, Dental Education, Kinesthetic, Aural, Multimodal.

\section{INTRODUCTION:}

Do all the individuals have the same preferred way of learning? Are there any differences in learning perceptions of students belonging to different academic years, background, culture or geographical distributions? Are these differences also gender based? All of these questions are termed very important while constituting a thorough academic course and syllabus. ${ }^{1}$ Researchers over the period of time have proposed that each and every individual has a different sensory modality. Every student attains knowledge and learns new information according to one's distinctive learning style. Awareness of the learning perceptions of their students is of paramount importance for the teachers. ${ }^{2,3}$ This may identify problems in their learning and may also improve overall academic performance of the students. Having a widespread attitude for teaching, also improves the communication between the student and the educator. In order to maximize the outcome, the learning styles of students need to be recognized so that the teaching style can also be tailored according to the preferred learning methods. If a person chooses one learning preference, they are classified

Amtul Anum,
Lecturer, Department of Orthodontics
Bahria University Medical and Dental College, Karachi
E-mail: aanum.s@hotmail.com
Tabassum Ahsan Qadeer
Associate Professor, Head of Orthodontics Deapartment
Bahria University Medical and Dental College, Karachi
Received: 23-01-2019

as unimodal and if a person displays two or more equally predominant preferences, he has multimodal learning preference. ${ }^{4,5}$ The multimodal group is further classified into bimodal, trimodal and quadmodal preferences. There are numerous ways of delivering knowledge and four major types are characterized by VARK questionnaire.

VARK is a questionnaire consisting of 16 multiple choice questions, established by Neil Fleming, an educator and a teacher in New Zealand, who brought forward a model for differential learning. The internet links for the VARK homepage and questionnaire have been given in the references. ${ }^{2,6}$

VARK is an acronym for Visual, Auditory or Aural, Reading and Kinesthetic respectively. Visual learning preference is a concept in which students prefer to learn with visual aids such as pictures, figures, diagrams and graphical representations. Those who prefer aural mode of learning, adapt best to lectures, discussions and small-group learning. $\mathrm{R}$ in the VARK stands for reading and it's a preference for those students who prefer to learn best from reading from books or written notes. Lastly, individuals who prefer kinesthetic sensory mode, learn well when they are taught with demonstrations, mockups, case-based learning, community trips and role plays. ${ }^{7}$

The VARK questionnaire is quite intricate, self-explanatory and easy to appraise, therefore it is used in studies to determine learning preferences of students belonging to diverse fields. Awareness about their own perceptiveness can enable students to amend their study methods and also 
help lecturers to modify their teaching system according to the students' needs. ${ }^{8}$ Many studies using the VARK questionnaire have indicated that students of health sciences prefer to use two or more sensory modalities rather than a single mode of learning. The learning style of students may be unimodal or multimodal. ${ }^{9}$

It is very important to determine the learning preferences of the students in order to create a learning environment suitable for all preferences and since there has not been enough studies conducted on Pakistani population, our study aimed to find the learning preferences of students at Bahria University of medical and dental college by using the VARK questionnaire. This questionnaire helps students and teachers understand their best approach to learning and also serves as a guideline for teaching and learning. The study also aimed to determine if there were any gender variations in learning styles of students.

\section{METHODOLOGY:}

This was a cross sectional clinical study, conducted at Bahria University of Medical and Dental College in Karachi, Pakistan from September 2018 to December 2018 using both clinical and non-clinical students as subjects. The study was approved by the ethical review committee, BUMDC No. $65 / 2018$. Sample size was estimated using the method of sample size for "single proportion" by using formula of single proportion with known population with margin of error $5 \%$, confidence interval for mean $95 \%$. The required sample size was found to be 278 out of which 150 were MBBS (30 each year), 100 BDS (25 each year) and 28 DPT ( 20 from $1^{\text {st }}$ year and 8 from $2^{\text {nd }}$ year). All the enrolled ungraduated students in MBBS, BDS and DPT were included in the inclusion criteria and House officers, residents were excluded from the study along with the students who did not consent to being included in the study.

For data collection, a consent was taken after which first Candidate was selected randomly and then every third student was selected for the study. The selected students were asked to fill a validated VARK questionnaire. VARK questionnaire consisted of 16 multiple choice questions, each with four different options. The students were asked to select more than one option if required. The data was kept anonymous, only gender and educational year were recorded. Filled forms were collected by the investigator.

Data was reported as the percentages of the students in each category of their learning preference. The number of students with their respective preferences was divided by the total number of responses to determine the percentage.

The data was assessed using SPSS software, version 23. Statistical differences regarding learning preferences among MBBS, BDS and DPT students and gender preferences among the subjects were made using chi square analysis and comparison between academic years was made with Fisher's exact test. $\mathrm{P}<0.05$ was considered significant.

\section{RESULT:}

Out of 278 students, $216(78 \%)$ were female and $62(22 \%)$ were male. When learning preferences were compared between all students it was observed that the predominant preference was unimodal (76.3\%) learning style followed by bimodal (18.3\%) and trimodal (5.4\%). No statistically significant difference was found between genders. The pattern of sensory mode preference is depicted in figure 1. *None of the students preferred the quadmodal learning preference. Kinesthetic $(40 \%)$ was found to be the most preferred unimodal method by the students. This was followed by aural $(37 \%)$ and reading $(12 \%)$ styles which were found higher in preference than visual (11\%). (Figure no.2). Amongst the bimodal learners, the combination AuditoryKinesthetic (AK) was the most preferred combination. Visual-Auditory-Read (VAR) was the most preferred trimodal combination. Furthermore, when the four models were compared between the genders, the difference was insignificant. Both the genders preferred the unimodal method followed by bimodal and trimodal methods as depicted in table no. 1. Both genders showed preference for kinesthetic method, followed by the aural and read and visual styles. When groups were compared based on academic variations, MBBS, BDS and DPT all preferred unimodal style of learning (Bar chart 1). However MBBS showed a preference for kinesthetic style (33.3\%) followed by Auditory (24.75\%), Read (11.3\%) and Visual (7.3\%) while BDS and DPT both preferred auditory sensory modality. BDS had Auditory (31\%) as the highest learning preference followed by Kinesthetic (30\%), Visual (9\%) and Read (8\%) methods. While DPT preferred Auditory (35.7\%), followed by kinesthetic (17.9\%), Visual (10.7\%) and the Read (3.6\%) as the lowest learning preference.

\section{DISCUSSION:}

This study was conducted to analyze the difference in learning styles of students in Bahria University of Medical and Dental College, Karachi, Pakistan. An interesting point was raised by James et al that significantly more weightage is given to other fields of medicine by our educational system as compared to nursing students, regarding the way knowledge is imparted to them. ${ }^{10}$ And this should be a point of research to check if it is true for our population as well.

VARK questionnaire is one of the thoroughly used methods to define and evaluate different sensory approaches of learning. ${ }^{11}$ It is crucial that such studies are conducted to identify major contributors that cause excessive failure rates in advanced medical and dental institutions and result in a substandard academic end result of the students. ${ }^{12}$ Recognition of these modalities meticulously aids the dental and medical teacher to adopt a differential teaching approach and select multiple teaching modalities in their educational curriculum. ${ }^{13}$ Having a thorough insight of students' various learning preferences also aids the student to learn faster and 
Figure No.1 - Percentages of Students With Preferred Mode of Learning

Percentages of Students with Preferred Mode of Learning

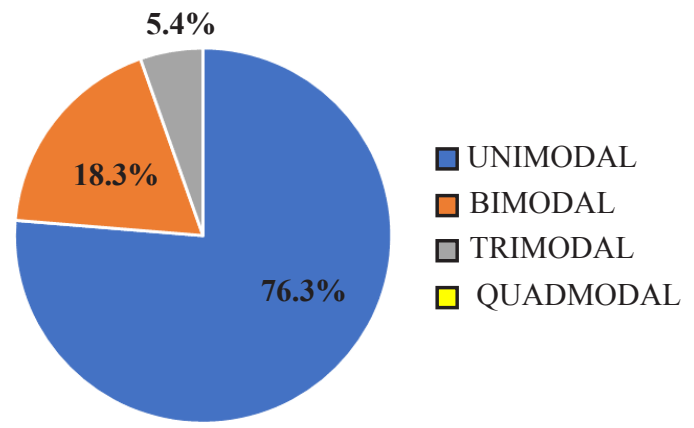

Figure No.2 - Percentages of Students Who Preferred Unimodal Mode of Learning

Percentages of Students with Preferred Unimodal Mode of Learning

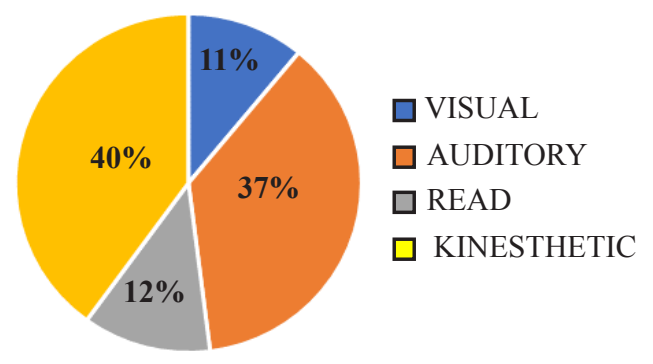

Table No.1 Vark Score And Gender Preferences

\begin{tabular}{|c|c|c|c|c|c|}
\hline \multicolumn{2}{|c|}{} & \multicolumn{5}{|c|}{ SENSORY MODALITY } \\
\hline \multicolumn{2}{|c|}{ Gender } & Unimodal & Bimodal & Trimodal & Quadmoal \\
\hline \multirow{2}{*}{ Female } & Count & 163 & 40 & 13 & 0 \\
\cline { 2 - 6 } & $\%$ & $75.0 \%$ & $19.0 \%$ & $6.0 \%$ & $0.0 \%$ \\
\hline \multirow{2}{*}{ Male } & Count & 49 & 11 & 2 & 0 \\
\cline { 2 - 6 } & $\%$ & $79.0 \%$ & $18.0 \%$ & $3.0 \%$ & 0.0 \\
\hline
\end{tabular}

Bar Chart No.1 Preferred Sensory Modality Amongst MBBS, BDS AND DPT

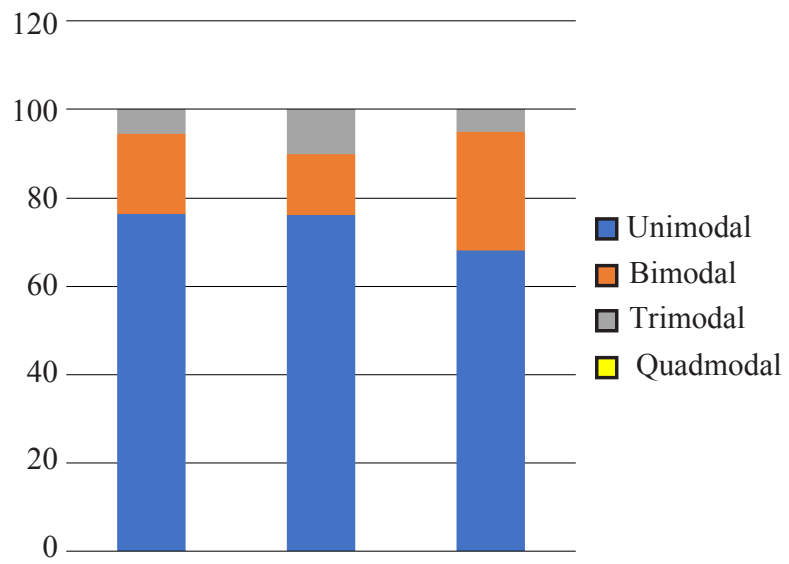

better and also motivates the teacher to move from their single mode of teaching to other methods. ${ }^{14}$ Moreover, according to Panambur et al., administration of learning preferences in the early educational stage of a student, can ominously improve quality and standard of education. ${ }^{15}$ Hence this research was conducted to analyze undergraduate students of all academic years and determine the influence of gender on learning styles. In the present study, the preferences of unimodal $(76.3 \%)$ learning, was the most dominant among the the undergraduate medical, dental and DPT students followed by bimodal $(18.3 \%)$ and trimodal (5.4\%) method of learning. This was similar to a study conducted by Liew SC et al, in which 343 respondents $(81.9 \%)$ had adopted unimodal learning style while the remaining 76 students (18.1\%) embraced multimodal learning styles. ${ }^{16}$ The chief sensory methodology of learning among unimodal learners was Kinesthetic ( $40 \%)$ followed by aural $(36 \%)$ and read (12\%) styles which were found higher in preference than visual (10\%) learning method. These results were in contrast to a study conducted by Nandita et al in which auditory modality was the most preferred unimodal learning style amongst both male (45.8\%) and female (50\%) students followed by the kinesthetic mode $(41.7 \%$ males and $38.64 \%$ females). Contrary to other studies conducted using VARK questionnaire, none of the students preferred the quadmodal learning preference. This could be as a result of the predominantly more unimodal method of learning being carried out in most pre-medical colleges. ${ }^{17}$ As observed by Samarakoon et al, pre-university education is often augmented with private tuition classes to promote strategic learning in order to have a satisfactory performance at the university entrance examination. Pre-clinical students tend to have a prominent auditory learning preference, however these learning styles do seem to change as they move up the ladder of medical education. A shift is observed from a more preferred auditory to predominantly kinesthetic learning from first to final years. Unfortunately, despite there being a cohesive modular base curriculum and assessment methods such as problem-based learning, case-based learning, tutorials and assessments, the ultimate learning styles do not appear to have changed significantly over the five years of undergraduate medical education, as evidenced by minimal change in the proportion of multimodal learners $(69.9 \%$ among first years to $68.5 \%$ among final years).${ }^{18} \mathrm{An}$ increase in academic performance has been seen in a study among Jordanian nursing students, where Problem-Based-Learning (PBL) was introduced as an improvement to the conventional teaching methods. A significant progress in learning style and increase in the percentage of multimodal learners in pre and post-tests, was seen after introduction of PBLs in a Jordanian study. Thus, it is likely that teaching strategies which promote active learning such as group discussions, debates and role playing may enhance the learning experience of students. ${ }^{19}$ When the mode of learning of MBBS, DPT 
and BDS were compared, the end result was also insignificant. Other researchers who studied the learning preferences of first, second and third year medical and dental students found that a small minority of students $(14.9 \%$ from medical and $30.7 \%$ from dental) preferred multimodal styles. Study by Haq HM et al, involving first year dental students in Turkey concluded that multimodal learning style was prevalent making up $64.12 \%$ of the total sample. ${ }^{20}$ This highlights the convenience of VARK questionnaire. It lets the students ascertain their own learning style, which may also contrast from their own insight. Having a thorough knowledge about your own learning behavior helps in improvising the overall academic performance and encourages active learning in the student.

Course curriculum in our college meticulously consists of lectures using multimedia, whiteboard teaching, hands-on demonstrations and small-group learning as well. Unimodal learners who tend who have a kinesthetic mode of preference are specially catered in our practicing methods. More over the passive lecture method is highly disregarded and the substance in the presentation is organized in such a manner that the topic becomes more interactive, comprehensible and can be carried out during a restricted amount of time. ${ }^{21}$ For students who prefer the aural method of learning, spoken sessions and lectures should be organized in such a manner that would enhance their ability to grasp the information. ${ }^{22}$

Our results showed no gender disparity and were similar to the study conducted by Urval et al. in 2015 who also did not find any significant differences between genders in any of the learning styles. ${ }^{8}$ On the contrary Wehrwein et al.'s study on physiology students and Nuzhat et al.'s study on medical students found that females preferred kinesthetic styles in contrast to males. ${ }^{23,24,25}$ This disparity between different studies could be because of any variance in educational year, age, society and the methods of education to these students were exposed to during their school and college years and gender of the research participants.

To sum up, if teaching methods are presented in such a way that the learning becomes pleasurable, the teacher will be able to understand the student more rather than expecting the students to become compliant to the passive teaching methods. Based on our study, it can be stated that it would be ideal for an institution to recognize VARK's four models and incorporate all in their teaching methodology to cater to the learning preferences of all the students.

Our study has a few limitations. It does not report whether changing the teaching system according to VARK learning style increases academic performance. The sample size was small and the students were selected from a single educational institution. Therefore research conducted in this department should further include a higher sample size, accommodate more educational institutions and also keep a track of the learning preferences among the students throughout their educational duration. However, our study upholds the concept of learning in multiple ways in accordance with the student's own acuities. It encourages learners and educators both to acknowledge the fact that the method of learning is as essential as the knowledge being conveyed.

The results of this study gives us a direction for constructing a more kinesthetic oriented learning system for the students. Every individual has his own insights and not all students are catered to by a single unreceptive lecture method.

\section{CONCLUSION:}

It was concluded that the undergraduate medical, dental and DPT students prefer unimodal method of learning despite of educational and academic differences. Amongst the unimodal learners, the most common method was kinesthetic followed by aural. Gender differences were also insignificant.

\section{REFERENCES:}

1) Choudhary R, Dullo P, Tandon RV. Gender differences in learning style preferences of first year medical students. Pak J Physiol. 2011; 7(2):42-5.

2) Wongsuphasawat K, Sittiprapaporn P. Preferred learning styles of Thai learners in anti-aging and regenerative sciences. Asian Journal of Medical Sciences. 2018; 9(6):14-9.

3) Shenoy N, Shenoy A. The perceptual preferences in learning among dental students in clinical subjects. Journal of clinical and diagnostic research: JCDR. 2013; 7(8):1683.

4) Peyman H, Sadeghifar J, Khajavikhan J, Yasemi M, Rasool $\mathrm{M}$, Yaghoubi YM et al Using VARK approach for assessing preferred learning styles of first year medical sciences students: a survey from Iran. Journal of clinical and diagnostic research: JCDR. 2014; 8(8):GC01.

5) Haq SM. Students' learning styles require modified teaching strategies. Journal of Rawalpindi Medical College. 2012; 16(2):191-3.

6) Fleming ND. I'm different; not dumb. Modes of presentation (VARK) in the tertiary classroom. In Research and development in higher education, Proceedings of the 1995 Annual Conference of the Higher Education and Research Development Society of Australasia (HERDSA), HERDSA 1995; 18: 308-13.

7) Shah K, Ahmed J, Shenoy N, Srikant N. How different are students and their learning styles? International Journal of Research in Medical Sciences. 2017; 1(3):212-5.

8) Mehdipour M, Mortazavi H, Yazdani J, Namdari M, Moradi M. Learning Styles of Dental Students at Shahid Beheshti University of Medical Sciences Using VARK Questionnaire. Iranian Journal of Medical Education. 2018; 18:176-82.

9) AlQahtani N, AlMoammar K, AlBarakati S, AlKofide E, Taher S. ONLINE SUBMISSION. Learning. 2018.

10) James $S$, D'Amore A, Thomas T. Learning preferences of first year nursing and midwifery students: Utilising VARK. Nurse education today. 2011; 31(4):417-23.

11) Horton DM, Wiederman SD, Saint DA. Assessment outcome is weakly correlated with lecture attendance: influence of learning style and use of alternative materials. Advances in physiology education. 2012; 36(2):108-15. 
12) Daud S, Kashif R, Chaudhry AM. Learning styles of medical students. South East Asian Journal of Medical Education. 2014; 8(1):40-6.

13) Al-Saud LM. Learning style preferences of first-year dental students at King Saud University in Riyadh, Saudi Arabia: influence of gender and GPA. Journal of Dental Education. 2013; 77(10):1371-8.

14) Urval RP, Kamath A, Ullal S, Shenoy AK, Shenoy N, Udupa LA. Assessment of learning styles of undergraduate medical students using the VARK questionnaire and the influence of sex and academic performance. Advances in physiology education. 2014; 38(3):216-20.

15) Panambur $S$, Nambiar V, Heming T. Learning style preferences of preclinical medical students in Oman. Oman medical journal. 2014; 29(6):461.

16) Liew SC, Sidhu J, Barua A. The relationship between learning preferences (styles and approaches) and learning outcomes among pre-clinical undergraduate medical students. BMC medical education. $2015 ; 15(1): 44$.

17) Gebru AA, Nasrabadi AN, Nigussie AW, Kahsay WG. Assessment of postgraduate international students' learning preference's at Tehran University of Medical Sciences, Tehran, Iran. Journal of Medical \& Allied Sciences. 2016; 6(1):14.

18) Samarakoon L, Fernando T, Rodrigo C, Rajapakse S. Learning styles and approaches to learning among medical undergraduates and postgraduates. BMC medical education. $2013 ; 13(1): 42$.
19) D'Amore A, James S, Mitchell EK. Learning styles of firstyear undergraduate nursing and midwifery students: A crosssectional survey utilising the Kolb Learning Style Inventory. Nurse education today. 2012; 32(5):506-15.

20) Haq SM. Students' learning styles require modified teaching strategies. Journal of Rawalpindi Medical College. 2012; 16(2):191-3.

21) Bhagat A, Vyas R, Singh T. Student's awareness of learning styles and their perceptions to a mixed method approach for learning. International Journal of Applied and Basic Medical Research. 2015; 5(1):S58.

22) Lujan HL, DiCarlo SE. First-year medical students prefer multiple learning styles. Advances in physiology education. 2006; 30(1):13-6.

23) Sarabi-Asiabar A, Jafari M, Sadeghifar J, Tofighi S, Zaboli $\mathrm{R}$, Peyman $\mathrm{H}$, et al. The relationship between learning style preferences and gender, educational major and status in first year medical students: a survey study from iran. Iranian Red Crescent Medical Journal. 2015; 17(1).

24) Nuzhat A, Salem RO, Quadri MS, Al-Hamdan N. Learning style preferences of medical students: a single-institute experience from Saudi Arabia. Int J Med Educ. 2011; 2:703.

25) Wehrwein EA, Lujan HL, DiCarlo SE. Gender differences in learning style preferences among undergraduate physiology students. Advances in physiology education. 2007; 31(2):1537. 